\title{
Three types of dural suturing for closure of CSF leak after endoscopic transsphenoidal surgery
}

\author{
Takayuki Ishikawa, MD, Kazuhito Takeuchi, MD, PhD, Yuichi Nagata, MD, Jungsu Choo, MD, \\ Teppei Kawabata, MD, Tomotaka Ishizaki, MD, and Toshihiko Wakabayashi, MD, PhD
}

Department of Neurosurgery, Nagoya University, Nagoya, Aichi, Japan

\begin{abstract}
OBJECTIVE Transsphenoidal surgery (TSS) is commonly used for anterior skull base surgery, especially in the sella turcica (sellar) region. However, because of its anatomical position, CSF leakage is a major complication of this approach. The authors introduced a new grading reconstruction strategy for anterior skull base surgery with continuous dural suturing in 2013. In this paper the authors report on their methods and results.
\end{abstract}

METHODS All patients with sellar or anterior skull base lesions that were removed with TSS or extended TSS by a single neurosurgeon between April 2013 and March 2017 at Nagoya University Hospital and several cooperating hospitals were retrospectively identified. Three methods of suturing dura were considered, depending on the dural defect.

RESULTS There were 176 TSS cases (141 conventional TSS cases and 35 extended endoscopic TSS cases) and 76 cases of Esposito's grade 2 or 3 intradural high-flow CSF leakage. In the high-flow CSF leak group, there were 3 cases of CSF leakage after the operation. The rates of CSF leakage after surgery corresponding to grades 2 and 3 were $2.9 \%$ $(1 / 34)$ and $4.7 \%(2 / 42)$, respectively.

CONCLUSIONS Dural suturing is a basic and key method for reconstruction of the skull base, and continuous suturing is the most effective approach. Using this approach, the frequency of cases requiring a nasoseptal flap and lumbar drainage can be reduced.

https://thejns.org/doi/abs/10.3171/2018.4.JNS18366

KEYWORDS CSF leak; transsphenoidal approach; dural reconstruction; shoelace suture; surgical technique; skull base

$\mathrm{D}$ EVELOPMENT of extended endoscopic transsphenoidal surgery (EETSS) has enabled neurosurgeons to resect many skull base tumors with minimal invasiveness. However, this approach requires removal of the skull base bone and opening of the arachnoid or third ventricle; consequently, CSF leakage after the surgery is a common complication of this procedure.

Many endoscopic neurosurgeons have reported various reconstructions of the skull base to prevent CSF leakage. Gasket seal ${ }^{6}$ and bath-plug methods ${ }^{16}$ have been reported as simple and easy techniques for such reconstruction, and multilayer closure has been reported to be effective. Use of a fat graft, fascia lata graft, sphenoidal mucosa, ${ }^{2}$ and nasal septal flap ${ }^{8}$ have been reported, and additional procedures such as lumbar drainage have also been reported as reliable approaches for prevention of CSF leakage after surgery. ${ }^{5}$

Some authors have reported the effectiveness of dural suturing. ${ }^{2,7,9,13,15}$ Nishioka et al. reported that the rate of CSF leakage after surgery was reduced by dural suturing compared to the rate before they introduced suturing. $.^{13} \mathrm{Al}-$ though most of these instances involve multiple single sutures, we have performed continuous dural suturing for reconstruction after extended TSS, as previously reported.$^{15}$ We believe that the best feature of continuous suturing is the tight closure at the dural layer, and this technique is reliable and feasible for every neuroendoscopist with appropriate training.

We have used the grading reconstruction strategy since 2013, depending on the size of the dural defect. In this report, we describe our technique of skull base reconstruction, including continuous dural suturing, and analyze its outcomes.

\section{Methods}

We retrospectively collected all the medical, imaging, 

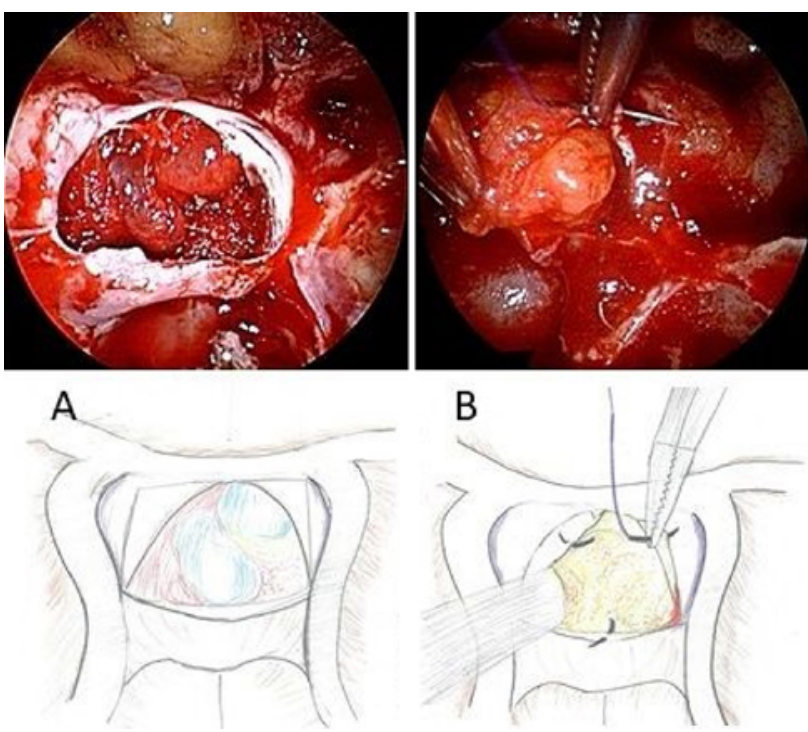
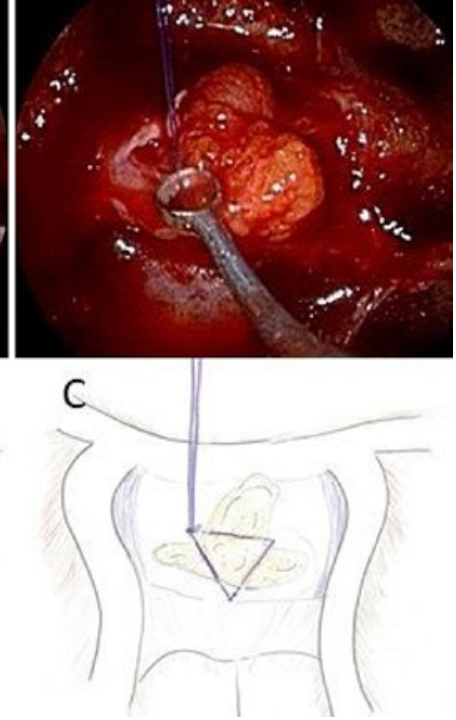

FIG. 1. Dural reconstruction for TSS. Intraoperative views (upper row) and illustrations of these views (lower row). A: The view after removal of a sellar tumor. B: The view during dural suturing. We usually suture 3 points of the dura like a triangle. We sometimes suture the dura more tightly when there is a moderate dural defect or grade 2-3 CSF leaks. C: The view after dural suturing. Copyright Takayuki Ishikawa (lower row). Published with permission. Figure is available in color online only.

operative, and pathological data of consecutive patients who underwent endoscopic TSS at Nagoya University Hospital and several satellite hospitals between April 2013 and March 2017.

\section{Operative Procedure}

We always prefer taking the paraseptal approach from a single nostril. When additional lateral exposure is needed, we open the ethmoidal sinus from the side of the middle turbinate without resecting any of the turbinates. If the patient is very young, and his or her nostrils are too small to pass two manipulators and a 4-mm endoscope into the sphenoid sinus via a single nostril, we use the bilateral nostril approach. After removal of tumors, we start the reconstruction. We introduce the graded repair strategy as shown below.

\section{Type 1: Conventional Endoscopic TSS Group (Dural Suturing)}

The representative lesion for the type 1 group is a pituitary adenoma and Rathke's cleft cyst limited to the sellar region. In this group, the extent of dural opening was small, limited to the sellar region. These cases correspond to Esposito's grade 2. ${ }^{4} \mathrm{We}$ cut the dura in an inverse " $\mathrm{T}$ " or "Y" shape. After tumor removal, fat tissue from a region slightly anterior to the navel is introduced into the sellar region, and the dura is sutured in the shape of a triangle (Fig. 1). Subsequently, fibrin glue is sprayed on the dura. Additional procedures such as lumbar drainage, sinus balloon placement, or insertion of a flap are not necessary.

\section{Type 2: Extended Endoscopic TSS Without Considerable Dural Defect Group ("Shoelace" Dural Suturing With Fat)}

The representative lesion for the type 2 group is a craniopharyngioma (not invading the dura), suprasellar arachnoid cyst, and Rathke's cleft cyst with extension to the suprasellar region. In this group, the sella turcica and some parts of the planum sphenoidale are opened, and the arachnoid is also opened, leading to considerable CSF leakage. A part of this group corresponds to Esposito's grade 3, with intact dura; hence, there is no need to remove the dura. The edges of the dura are close, but are not sufficiently close for tight suturing.

For this group, as we previously reported, we performed continuous dural suturing with fat; we call this the "shoelace technique." 15 This technique is explained below (Fig. 2, Video 1).

VIDEO 1. Clip showing the shoelace technique (Type 2). First, you start by anchoring the rod-shaped fat tissue with a double-armed suture at the top of the dural incision and make a square knot. Then you suture the middle of the fat and dural edge in a zig-zag fashion. After suturing to the dura of the tuberculum sellae, you put another round-shaped fat graft into the sellar region and make more sutures at the bottom of the dural incision. Copyright Takayuki Ishikawa. Published with permission. Click here to view.

We use two small pieces of fat from the abdominal subcutaneous fat layer, one with a round shape and the other rod-shaped. We suture both sides of the dura at the incised end of the planum sphenoidale using a double-armed suture with 6-0 Prolene (Johnson \& Johnson). We then insert one suture at the end of the rod-shaped fat, insert it into the subdural space in the planum sphenoidale, and ligate the suture. After fixation of the fat, we suture the dura and fat continuously in a zig-zag fashion to the point of the tuberculum sellae. Finally, we insert the round fat tissue into the dead space of the sellar region, and then suture the dura mater at the bottom of the sellar region, securing it with a strong knot.

After continuous suturing, we apply additional fat on the surface of the dura and then perform rigid reconstruction with LactoSorb (Zimmer Biomet), which is an 
absorbable plate, and then spray fibrin glue on it. When radiotherapy for the sellar region or chemotherapy is anticipated as adjuvant therapy, we add a nasoseptal flap, and occasionally use a sinus balloon for approximately 4 days. Lumbar drainage is not used.

\section{Type 3: Extended Endoscopic TSS With Considerable Dural Defect Group (Continuous Dural Suturing With Front Rectus Sheath)}

The representative lesion for the type 3 group is a tuberculum meningioma. The technique is appropriate for cases such as tuberculum meningioma, chordoma, giant pituitary adenoma, and craniopharyngioma invading the dura, which should be removed. The entire group corresponds to Esposito's grade 3.

We use a front rectus sheath and the fat tissue above it as the graft tissue. A 4- to 5-cm incision is made at the right lower abdomen. The first suture of the dura is performed in the same way as in the shoelace technique, using fascia instead of fat tissue. After fascia is anchored at the front end of the dural incision and inserted into the subarachnoid space, continuous suturing of the dura and fascia is performed from the planum sphenoidale to the bottom of the sellar region on both sides. A tight ligation is performed at the bottom. We then apply fat on the surface of the dura and fascia, and fix LactoSorb for rigid reconstruction; fibrin glue is sprayed on the surface (Fig. 3 , Video 2).

VIDEO 2. Clip showing continuous dural suturing (type 3). First, as with the shoelace technique, you start by anchoring the fascia with a double-armed suture at the top of the dural incision and make a knot. Then, you put the edge of the fascia in the dura so as to become an inlay. Next you suture both sides of the dura and fascia continuously. Copyright Takayuki Ishikawa. Published with permission. Click here to view.

In meningioma cases we routinely used a nasoseptal flap, and in cases of other pathologies we used it depending on the dural defect size, the patient's age, and whether radiotherapy or chemotherapy was anticipated or not. A lumbar drain was not used, except in case of complications. This method can also be used in cases of clival chordomas or chondrosarcomas.

\section{Postoperative Management}

We did not routinely use a lumbar drain in any intraoperative CSF leak grade and reconstruction methods. On the day of the operation patients were kept in bed. After checking the CT scan on the morning of postoperative day 1 , we permit patients to walk and eat. An otolaryngologist checked the condition of the nostrils and cleaned the cavity approximately 1 week after surgery to detect a CSF leak and prevent nasal mucosal adhesion, which can lead to airway and olfactory dysfunction.

\section{Results}

We have performed extended endoscopic TSS (EETSS) for 178 cases. There were 2 cases for which we could not procure sufficient medical records or operative videos, and these were excluded from the analysis. Among the 176 cases, there were 76 cases of grade 2 or 3 intraoperative
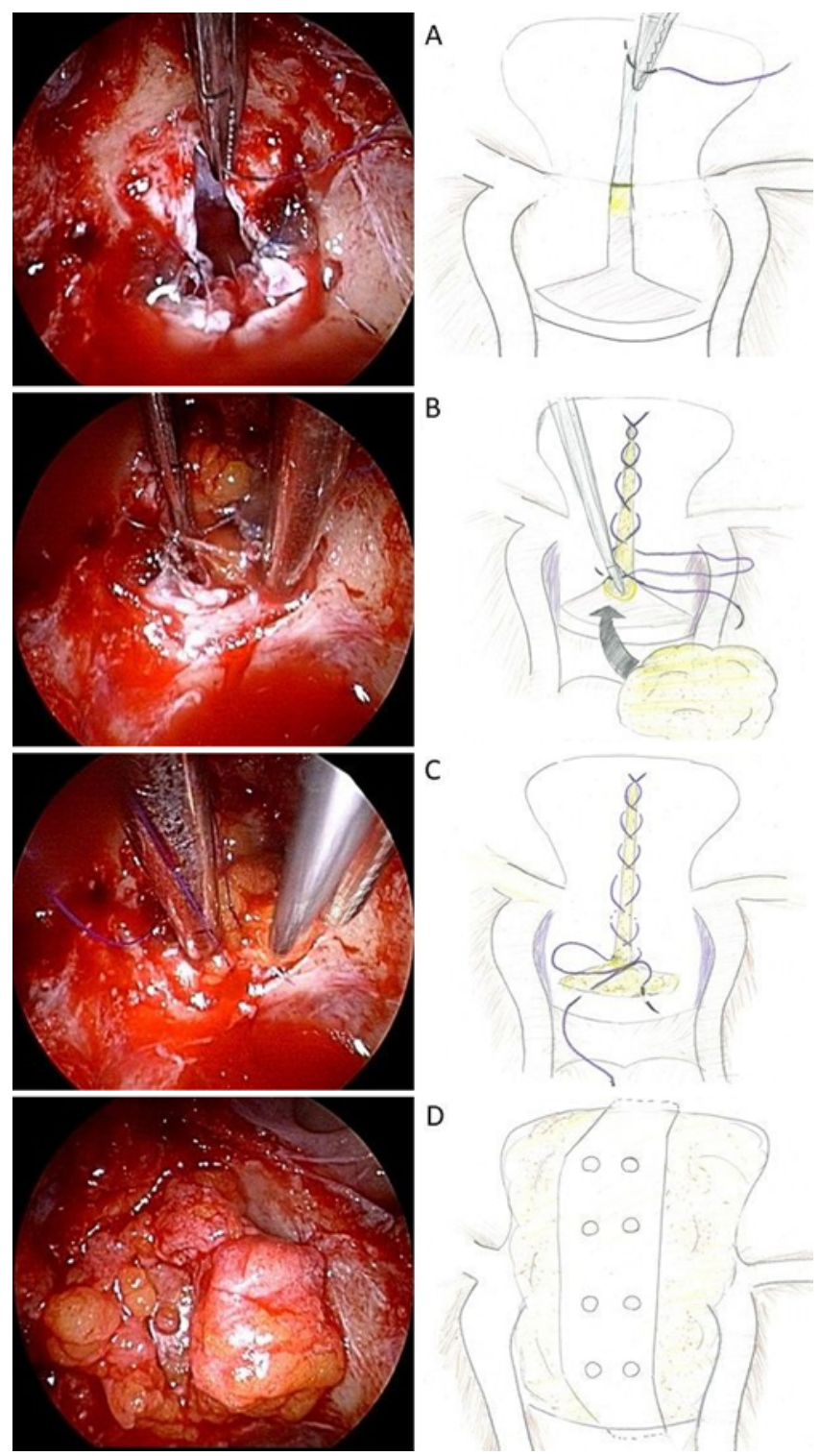

FIG. 2. Shoelace technique for extended TSS without a dural defect. Intraoperative views (left column) and illustrations of these views (right column). A: First we anchored the dura with a double-armed suture at the top end of the dural incision (planum sphenoidale side). B: Next we run the suture of the planum sphenoidale dura with stitches made alternately on both sides of the suture. At that time, you should suture the fat simultaneously. After suturing near the tuberculum sellae, another round-shaped fat tissue is inserted into the sellar region (arrow). C: After inserting fat, you suture the dura of the bottom of the sellar region, and make a knot. D: After suturing, you put another fat graft on the surface of the dura and fix it with LactoSorb or septal bone. Copyright Takayuki Ishikawa (right column). Published with permission. Figure is available in color online only.

CSF leakage. The pathologies are shown in Table 1. We performed simple dural suturing (type 1), "shoelace" suturing (type 2), and continuous suturing with fascia (type 3 ) in 41, 23, and 12 cases, respectively (Table 2). A nasoseptal flap was used in 3 and 9 cases of type 2 and type 3, respectively. No lumbar drain was introduced from just af- 

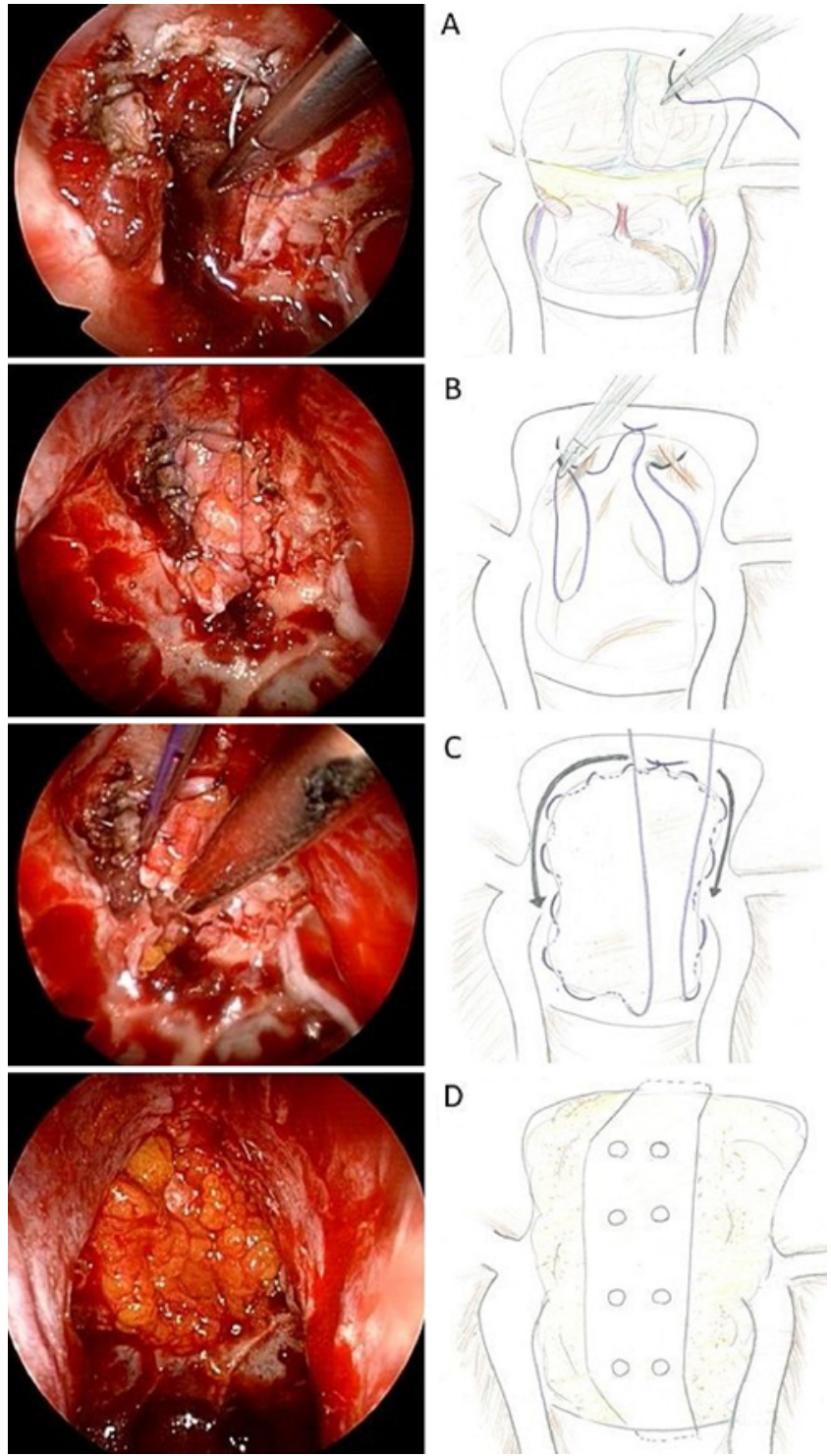

D

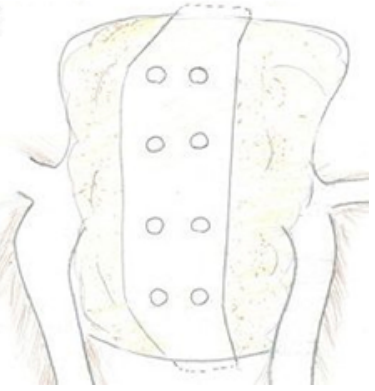

FIG. 3. Continuous dural suture with fascia for extended TSS with a dural defect. Intraoperative views (left column) and illustrations of these views (right column). A: You begin by anchoring the dura with a doublearmed suture at the top end of the dural incision (planum sphenoidale side). B and C: Next you suture both sides of the dura and fascia from the planum sphenoidale to the bottom of the sellar region. Arrows indicate the direction of the suturing. D: After suturing, you put another fat graft on the surface of the dura, and fix it with LactoSorb or septal bone. Copyright Takayuki Ishikawa (right column). Published with permission. Figure is available in color online only.

ter the operation. We recorded 3 cases of CSF leakage after operations, which required additional procedures. The overall CSF leakage rate was $3.9 \%$ (3/76), and the individual rates for the approaches were $2.4 \%(1 / 41)$ in type 1 , $4.3 \%(1 / 23)$ in type 2 , and $8.3 \%(1 / 12)$ in type 3 (Table 2$)$. Converting these rates to the rates using Esposito's grades, the rates of Esposito grades 2 and 3 were 2.9\% (1/34) and $4.7 \%$ (2/42), respectively. The cases of CSF leakage after operation are illustrated below (Table 3 ).

The first instance of CSF leakage was a case of non-
TABLE 1. Characteristics of the study population

\begin{tabular}{lc}
\hline \multicolumn{1}{c}{ Characteristics } & Value \\
\hline Mean age (range), yrs & $56.7(4-87)$ \\
\hline Males/females & $32 / 44$ \\
\hline Mean BMI (range), $\mathrm{kg} / \mathrm{m}^{2}$ & $23.1(15-33.1)$ \\
\hline Pathology & 38 \\
\hline Nonfunctioning pituitary adenoma & 1 \\
\hline Prolactinoma & 4 \\
\hline Growth hormone-producing pituitary adenoma & 3 \\
\hline Suprasellar arachnoid cyst & 15 \\
\hline Craniopharyngioma & 11 \\
\hline Meningioma & 1 \\
\hline Mixed germ cell tumor & 3 \\
\hline Rathke's cleft cyst & 76 \\
\hline Total
\end{tabular}

functioning pituitary adenoma (NFPA), in which we performed conventional TSS and dural suturing (type 1). Intraoperative CSF leakage corresponded to Esposito's grade 2 . One week after surgery, obvious rhinorrhea was detected, and CT showed worsening of pneumocephalus, so the patient received lumbar drainage. He remained in bed for another week but the CSF leak did not stop. We then performed a reoperation. During reoperation, we identified the leakage point between fat tissue and the right carotid artery ( $\mathrm{C} 4$ portion). Then we performed additional dural suturing and rigid construction with LactoSorb, and sprayed fibrin glue on the surface.

The second instance involved a case of suprasellar arachnoid cyst. We performed EETSS and the dural defect was slight, so we performed shoelace dural suturing and rigid reconstruction with LactoSorb in the usual fashion (type 2). But the patient felt the increase of rhinorrhea on postoperative day 3 . Therefore, we inserted a lumbar drain and observed for 3 days. After the 3 days rhinorrhea was not detected and the drain was removed. On postoperative day 9 rhinorrhea occurred again and we again performed lumbar drainage. However, the rhinorrhea did not stop, so we decided to perform a reoperation. During reoperation we could not detect apparent CSF leakage from the suturing site. However, to be thorough, we made additional dural suturing, sprayed fibrin glue, and used a nasoseptal flap and sinus balloon.

The third instance involved a case of tuberculum sellae meningioma (TSM). We performed EETSS and a type 3 reconstruction method with a nasoseptal flap. The patient experienced slight continuous nasal discharge without any other symptoms on postoperative day 7. However, because the patient had undergone the operation in a cooperating hospital, we decided to perform an early reoperation. During reoperation we did not identify any apparent CSF leakage, even using the Valsalva method; hence, we simply resprayed the surface with fibrin glue.

As a result, CSF leakage was successfully stopped for all 3 patients using the methods described above. There was no patient who suffered from meningitis. We rarely use a lumbar drain, and a lumbar drain was used for only 
TABLE 2. Results of reconstruction of skull base

\begin{tabular}{lccccl}
\hline \multicolumn{1}{c}{ Dural Reconstruction } & No. of Pts & Nasoseptal Flap & Sinus Balloon & CSF Leak (\%) & Pathology of CSF Leak Cases \\
\hline Dural suturing & 41 & 0 & 0 & $1(2.4)$ & NFPA $(n=1)$ \\
\hline Shoelace technique & 23 & 3 & 2 & $1(4.3)$ & Suprasellar arachnoid cyst $(n=1)$ \\
\hline Continuous fascia suturing & 12 & 9 & 3 & $1(8.3)$ & TSM $(n=1)$ \\
\hline
\end{tabular}

Pts = patients

We did not routinely use a lumbar drain; in this study we used a drain in only two cases and it was used several days ( 3 and 7 ) after surgery when CSF leakage was suspected from clinical symptoms and images.

2 cases of postoperative CSF leakage (first and second cases), but the patients eventually underwent a reoperation for CSF leak.

\section{Discussion}

The endoscopic transsphenoidal approach is rapidly gaining popularity because of its minimal invasiveness and wide view. In particular, since the introduction of EETSS, increasing numbers of skull base tumors have been removed using this approach. Although this approach has some limitations, such as a relatively small size, it has facilitated the removal of skull base tumors with fewer neurological complications. . $^{3,11}$

However, due to the removal of the skull base bone and dura, CSF leakage has been a major complication until recently. Esposito et al. advocated the grading of repair depending on intraoperative CSF leakage and dural defect. ${ }^{4}$ We agree with this grading of repair strategy, however, our approach was different from those authors. They reported good results; briefly, only $6.7 \%$ of the patients with grade 3 intraoperative CSF leakage experienced postoperative CSF leakage (Table 4). However, the authors used a titanium mesh for rigid reconstruction. Such metallic instruments may lead to artifacts during postoperative MRI or hinder subsequent radiation therapy. The gasket seal is an easy and effective method of EETSS reconstruction. Garcia-Navarro et al. reported the rate of postoperative CSF leakage to be $5.2 \%^{6}$ (Table 4), but these authors used a nasoseptal flap in all cases. The nasoseptal flap is reported to be effective, ${ }^{8}$ but also causes olfactory impairment. ${ }^{1} \mathrm{Al}-$ though in some cases the nasoseptal flap is indispensable, it is not required in any of the EETSS cases. Therefore, it is crucial to identify and distinguish these cases carefully.

Studies have reported the importance of dural suturing in addition to multilayer reconstruction. . $^{2,7,9,13,14}$ These studies have reported good outcomes and have also reported methods for reducing difficulties in performing many sutures and making knots. We have now introduced a method of dural repair by continuous suturing for EETSS. The merit of continuous suturing is that it can maintain the same tension around fascia or fat. Because CSF leakage is considered to occur at the vulnerable points of dural reconstruction, continuous suturing may prevent the leakage by reducing such vulnerable points. The next merit is the reduced number of knots. In the sphenoid sinus, it is difficult and time-consuming to make many knots. In contrast, continuous suturing requires only two knots. Moreover, reducing the number of knots can reduce the risk of injuring the nasal mucosa while inserting manipulators, which is one of the reasons for impaired olfaction following surgery. Single or continuous suturing in a deep region is certainly difficult because of the small corridor. However, in craniotomy, surgeons typically close the dura as tightly as possible and subsequently spray fibrin glue. If there is a defect in the dura, it is closed with fascia or galea. In such cases, it is reasonable to suture the dura mater tightly in the skull base region where the CSF may easily leak because of its anatomy.

In addition, appropriate suturing reduces the need for additional procedures such as a nasoseptal flap or lumbar drain. We achieved equal or better results than previous reports with less frequent use of a lumbar drain or nasoseptal flap (Table 4). As mentioned above, the nasoseptal flap is a reliable approach for preventing CSF leakage but sometimes impairs olfactory function and quality of life (QOL). ${ }^{1}$ Although in certain cases this procedure is indispensable, we believe that alternative approaches are feasible for the cases without considerable dural defect. We performed shoelace suturing for 23 cases of grade 3 CSF leakage without a flap and drain. However, there was one case of postoperative CSF leakage; in all other cases, we succeeded in preserving the nasal structure. In addition, we basically used the paraseptal approach from a single

TABLE 3. The cases of CSF leakage after surgery

\begin{tabular}{|c|c|c|c|c|c|c|}
\hline \multirow[b]{2}{*}{ Pathology } & \multicolumn{2}{|c|}{1 st Op } & \multirow[b]{2}{*}{$\begin{array}{l}\text { NS } \\
\text { Flap }\end{array}$} & \multirow{2}{*}{$\begin{array}{c}\text { Timing } \\
\text { of CSF } \\
\text { Leakage }\end{array}$} & \multirow[b]{2}{*}{ LD } & \multirow[b]{2}{*}{ Method of $2 n d$ Op } \\
\hline & $\begin{array}{c}\text { Leakage } \\
\text { Grade }\end{array}$ & Method & & & & \\
\hline NFPA & 2 & Type 1 & No & POD 7 & Yes & Additional dural suturing, rigid reconstruction (LactoSorb), fibrin glue \\
\hline Suprasellar arachnoid cyst & 3 & Type 2 & No & POD 3 & Yes (twice) & Additional dural suturing, fibrin glue, nasoseptal flap, sinus balloon \\
\hline TSM & 3 & Type 3 & Yes & POD 7 & No & Fibrin glue \\
\hline
\end{tabular}

$L D=$ lumbar drainage; $N S=$ nasoseptal; $P O D=$ postoperative day.

The CSF leak was controlled in all cases. 
TABLE 4. Literature review of repair of anterior skull base reconstruction

\begin{tabular}{|c|c|c|c|c|c|c|}
\hline \multirow[b]{2}{*}{ Authors \& Year } & \multirow[b]{2}{*}{ Main Technique } & \multirow[b]{2}{*}{ Other Adjuvant } & \multicolumn{4}{|c|}{ CSF Leak After Op } \\
\hline & & & Overall & Grade $0-1$ & Grade 2 & Grade 3 \\
\hline \multicolumn{7}{|l|}{ Suture group } \\
\hline Present study & $\begin{array}{l}\text { Continuous dural suturing (w/ fat } \\
\text { or fascia), fat graft }\end{array}$ & $\begin{array}{l}\text { Grade } 3 \pm \text { lactate plate } \\
\pm \text { nasoseptal flap }\end{array}$ & $2.2 \%(4 / 176)$ & $1 \%(1 / 100)$ & $2.9 \%(1 / 34)$ & $4.7 \%(2 / 42)$ \\
\hline Hara et al., 2015 & $\begin{array}{l}\text { Dural suture, fat graft, sphenoidal } \\
\text { sinus mucosal flap }\end{array}$ & Grade 3 fascia suturing & $1.6 \%(2 / 125)$ & $0 \%(0 / 120)$ & $0 \%(0 / 30)$ & $4.5 \%(2 / 44)$ \\
\hline Amano et al., 2016 & $\begin{array}{l}\text { Dural suturing w/ sphenoid sinus } \\
\text { mucosal flap }\end{array}$ & \pm fat graft & $1.2 \%(6 / 500)$ & Data NA & Data NA & Data NA \\
\hline \multicolumn{7}{|l|}{ No-suture group } \\
\hline Esposito et al., 2007 & $\begin{array}{l}\text { Fat, collagen sponge, titanium } \\
\text { mesh }\end{array}$ & Grade 3 LD & $1.2 \%(4 / 340)$ & $0.77 \%(2 / 259)$ & $0 \%(0 / 51)$ & $6.7 \%(2 / 30)$ \\
\hline Kassam et al., 2008 & NS flap & Foley, collagen matrix & & & & $10.60 \%$ \\
\hline Luginbuhl et al., 2010 & Button (fascia lata) & $\pm \mathrm{LD}, \pm$ NS flap & & & & $10 \%(4 / 40)$ \\
\hline Garcia-Navarro et al., 2013 & Gasket seal closure & $\pm \mathrm{LD}, \pm \mathrm{NS}$ flap & & & & $4.3 \%(2 / 46)$ \\
\hline Fathalla et al., 2017 & LD & \pm NS flap, nasal trumpet & & & & $2.9 \%(1 / 35)$ \\
\hline
\end{tabular}

$\mathrm{NA}=$ not available.

nostril without any turbinectomy. In this method, the risk of touching the olfactory mucosa is minimal. Nasal malfunction is not a lethal complication but appears to reduce QOL. Furthermore, our data showed that our methods led to a reduction in the number of cases requiring a lumbar drain. A lumbar drain reduces CSF pulsation, ${ }^{5}$ which appears to be one of the major reasons for postoperative CSF leakage. Although a useful method, it is associated with the risk of nerve injury and infection. In addition, a lumbar drain involves the risk of wasting syndrome because patients require prolonged bed rest. Patients with wasting syndrome need additional hospitalization, which involves more cost. Elderly individuals in particular easily fall into this condition. In this study more than one-third of all patients (31/76) were older than 65 years, and the oldest was 87 years of age. Ahead of the world, Japan is becoming a super-aged society, so maintaining QOL after surgery is critically important not only for elderly individuals but also our society. Instead of inserting a lumbar drain, reliable reconstruction at operation is desirable to achieve early ambulation. To reduce the effect of CSF pulsation to the sellar floor we make a rigid reconstruction in high-flow CSF leak cases. Although we have used septal bone be- fore, we sometimes encounter bone that is too thin to sustain the sellar floor. We think LactoSorb is durable enough to sustain the floor and easily form the correct shape.

We use fat tissue in every method. We believe that fat tissue is suitable material for reconstruction because it can adhere to the surrounding tissue. However, it takes several days or weeks for the fat to adhere, therefore it may need additional fixation during that time. We sutured dura for fixation, ensuring a close contact between the dura and fat and preventing CSF leakage; this appears to ensure rapid and tight adhesion. Of course, there is a cosmetic problem due to harvesting fat tissue, but we try to make the scar inconspicuous by harvesting fat tissue from the slightly upper section of the navel with an approximately $1-\mathrm{cm}$ skin incision (Fig. 4).

The present approach has a few limitations. As might be expected, the corridor for TSS is small, and it is difficult to suture the dura mater under such a condition. However, appropriate training for suturing dura allows surgeons to safely and smoothly perform suturing in this small space. In the present study, the first instance of suturing required a considerable amount of time, but as we previously reported, after several such instances, we could complete

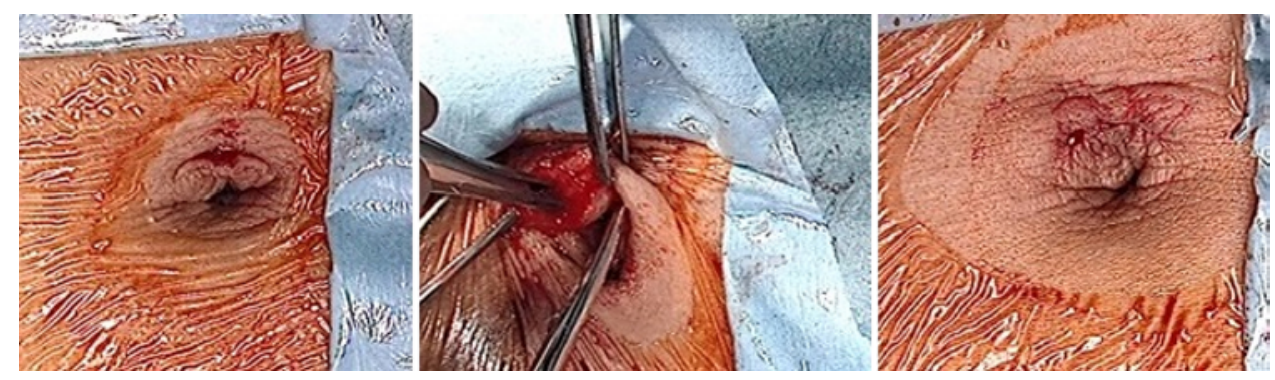

FIG. 4. Photographs of the skin incision for harvesting fat tissue. When we do not use fascia, we harvest fat tissue from just the upper part of the navel with a $1-\mathrm{cm}$ skin incision. Figure is available in color online only. 
continuous suturing with fat or fascia in approximately 30 minutes. In addition, suturing cannot be performed when the dural defect is quite large and the margin for continuous suturing cannot be secured. Fortunately, we did not encounter such cases in this period. If we encounter such cases, we would perform single suturing with fascia at all possible points and then introduce fat and LactoSorb to finally make a nasoseptal flap.

There were also a few limitations to this study. The study was retrospective and the number of patients was limited. In this study period we could not identify any risk factor of CSF leakage after TSS. In addition, we could not compare the suturing group and the other methods and groups directly. Compared with results from other studies previously reported, our results were not remarkably better, but we could achieve nearly equal results with less use of other adjuvant methods such as a lumbar drain and nasoseptal flap.

TSS has spread widely, and more skull base tumors will be removed using this approach. However, because of the anatomical features involved in this approach, CSF leakage is a critical problem. In this study we demonstrate novel reconstruction methods for this approach and achieved a low rate of CSF leak for all grades.

\section{Conclusions}

Dural suturing is a basic and key method for reconstruction of the skull base, with continuous suturing being the most effective approach. Tightly suturing the dura can reduce the need for additional procedures such as placement of a lumbar drain and insertion of a nasoseptal flap.

\section{References}

1. Alobid I, Enseñat J, Mariño-Sánchez F, de Notaris M, Centellas S, Mullol J, et al: Impairment of olfaction and mucociliary clearance after expanded endonasal approach using vascularized septal flap reconstruction for skull base tumors. Neurosurgery 72:540-546, 2013

2. Amano K, Hori T, Kawamata T, Okada Y: Repair and prevention of cerebrospinal fluid leakage in transsphenoidal surgery: a sphenoid sinus mucosa technique. Neurosurg Rev 39:123-131, 2016

3. Bander ED, Singh H, Ogilvie CB, Cusic RC, Pisapia DJ, Tsiouris AJ, et al: Endoscopic endonasal versus transcranial approach to tuberculum sellae and planum sphenoidale meningiomas in a similar cohort of patients. J Neurosurg 128:40-48, 2018

4. Esposito F, Dusick JR, Fatemi N, Kelly DF: Graded repair of cranial base defects and cerebrospinal fluid leaks in transsphenoidal surgery. Neurosurgery 60 (4 Suppl 2):295-304, 2007

5. Fathalla H, Di Ieva A, Lee J, Anderson J, Jing R, Solarski M, et al: Cerebrospinal fluid leaks in extended endoscopic transsphenoidal surgery: covering all the angles. Neurosurg Rev 40:309-318, 2017

6. Garcia-Navarro V, Anand VK, Schwartz TH: Gasket seal closure for extended endonasal endoscopic skull base surgery: efficacy in a large case series. World Neurosurg 80:563-568, 2013

7. Hara T, Akutsu H, Yamamoto T, Tanaka S, Takano S, Ishikawa $\mathrm{E}$, et al: Cranial base repair using suturing technique combined with a mucosal flap for cerebrospinal fluid leakage during endoscopic endonasal surgery. World Neurosurg 84:1887-1893, 2015

8. Horiguchi K, Murai H, Hasegawa Y, Hanazawa T, Yamakami I, Saeki N: Endoscopic endonasal skull base reconstruction using a nasal septal flap: surgical results and comparison with previous reconstructions. Neurosurg Rev 33:235-241, 2010

9. Ishii Y, Tahara S, Oyama K, Kitamura T, Teramoto A: Easy slip-knot: a new simple tying technique for deep sutures. Acta Neurochir (Wien) 153:1543-1545, 2011

10. Kassam AB, Gardner PA, Snyderman CH, Carrau RL, Mintz AH, Prevedello DM: Expanded endonasal approach, a fully endoscopic transnasal approach for the resection of midline suprasellar craniopharyngiomas: a new classification based on the infundibulum. J Neurosurg 108:715-728, 2008

11. Kitano M, Taneda M: Extended transsphenoidal surgery for suprasellar craniopharyngiomas: infrachiasmatic radical resection combined with or without a suprachiasmatic translamina terminalis approach. Surg Neurol 71:290-298, 2009

12. Luginbuhl AJ, Campbell PG, Evans J, Rosen M: Endoscopic repair of high-flow cranial base defects using a bilayer button. Laryngoscope 120:876-880, 2010

13. Nishioka H, Izawa H, Ikeda Y, Namatame H, Fukami S, Haraoka J: Dural suturing for repair of cerebrospinal fluid leak in transnasal transsphenoidal surgery. Acta Neurochir (Wien) 151:1427-1430, 2009

14. Sakamoto N, Akutsu H, Takano S, Yamamoto T, Matsumura A: Useful 'sliding-lock-knot' technique for suturing dural patch to prevent cerebrospinal fluid leakage after extended transsphenoidal surgery. Surg Neurol Int 4:19, 2013

15. Takeuchi K, Nagatani T, Wakabayashi T: How I do it: shoelace watertight dural closure in extended transsphenoidal surgery. Acta Neurochir (Wien) 157:2089-2092, 2015

16. Wormald PJ, McDonogh M: 'Bath-plug' technique for the endoscopic management of cerebrospinal fluid leaks. J Laryngol Otol 111:1042-1046, 1997

\section{Disclosures}

The authors report no conflict of interest concerning the materials or methods used in this study or the findings specified in this paper.

\section{Author Contributions}

Conception and design: Ishikawa. Acquisition of data: Ishikawa, Kawabata. Analysis and interpretation of data: Ishikawa. Drafting the article: Ishikawa. Critically revising the article: Ishikawa, Takeuchi. Reviewed submitted version of manuscript: Takeuchi, Nagata, Choo, Ishizaki, Wakabayashi. Approved the final version of the manuscript on behalf of all authors: Ishikawa. Administrative/technical/material support: Takeuchi. Study supervision: Takeuchi, Wakabayashi.

\section{Supplemental Information \\ Videos}

Video 1. https://vimeo.com/277437193.

Video 2. https://vimeo.com/277437203.

\section{Correspondence}

Takayuki Ishikawa: Graduate School of Medicine, Nagoya University, Nagoya, Aichi, Japan. ishikawa.takayuki@h.mbox. nagoya-u.ac.jp. 